\title{
Aplicações do Método Bick de Observação: Revisão Sistemática da Produção Científica Brasileira
}

\author{
Marisa Amorim Sampaio* (D), Maria Cristina Lopes de Almeida Amazonas (D), \\ \& Edilene Freire de Queiroz (D) \\ Universidade Católica de Pernambuco (UNICAP), Recife, PE, Brasil
}

\begin{abstract}
RESUMO - Trata-se de uma revisão sistemática da literatura acerca da produção científica brasileira sobre o método Bick de observação, buscando identificar e discutir suas possibilidades de desenvolvimento, do uso no ensino à aplicação na pesquisa acadêmica, analisando tendências e tensões. Foi realizado um levantamento em bases de dados nacionais e os resultados das pesquisas apontam que há uma ampliação e revitalização do Bick em aplicações avaliativas, preventivas e terapêuticas, assim como na academia, favorecendo a reflexão nas diferentes vertentes que o método oferece. Por fim, são discutidos aspectos sobre a pesquisa psicanalítica, reinterpretada na complexidade das implicações epistemológicas do pesquisar no contexto universitário.
\end{abstract}

PALAVRAS-CHAVE: observação, psicanálise, método Bick, pesquisa

\section{Applications of Infant Observation:A Systematic Review}

\begin{abstract}
The article, a systematic review of the literature about the Brazilian scientific production on Bick's Infant Observation, identified and discussed its possibilities of development, from the use in teaching to the application in academic research, analysing tendencies and tensions. This review was carried out in national databases and the results point out that there is a broadening and revitalization of infant observation in evaluative, preventive and therapeutic applications, as well as in academia, furthering a reflection on the different aspects that the method presents. Furthermore, we discussed aspects of psychoanalytic research, reinterpreted in the complexity of the epistemological implications of research in the university context.
\end{abstract}

KEYWORDS: observation, psychoanalysis, Bick's infant observation, research

$\mathrm{Na}$ produção do conhecimento, não se lida com um conceito único de ciência, mas com paradigmas de pensamento renovados; observa-se a necessidade de técnicas que incorporem na pesquisa as experiências subjetivas e intersubjetivas do pesquisador. Os processos de comunicação e interpretação são construções coletivas marcadas pelas condições relacionais, sócio-históricas e psíquicas dos sujeitos. O pesquisador, inserido e contextualizado na realidade, é parte dela, captando-a de modo reconstrutivo, apesar dos esforços pela suposta neutralidade e objetividade positivista (Demo, 2001).

Dentre os diferentes modos de reconstrução da realidade, a Psicanálise apresenta uma modalidade de tratamento, um método de investigação e o conhecimento fruto destes.
Clínica e pesquisa estão separadas por técnicas respectivas na condução dos fenômenos transferenciais, mas unidas pelo método, capital na produção do saber psicanalítico (Freud, 1923/1980). A experiência psicanalítica admite diversas possibilidades técnicas, que, como espécies, correlacionamse ao método psicanalítico como gênero. A pesquisa com o método psicanalítico, na modalidade fora do setting clínico, busca compreender, porém não interpretar junto ao outro os fenômenos transferenciais. O espaço psicanalítico é o locus para a pesquisa, ampliando os campos empíricos e utilizando o método para validar as pesquisas desenvolvidas fora do processo psicanalítico estrito, mas mantendo a uniformidade teórica (Lowenkron, 2004).

\footnotetext{
*E-mail: marisasampaio@hotmail.com

- Submetido: 24/03/2016; Revisado: 06/07/2017; Aceito: 31/07/2017.
} 
Quanto às possibilidades de pesquisa com Psicanálise, situamos o método Bick - ou técnica de Observação da Relação Mãe-Bebê na Família, como conhecido no Brasil (Souza, 2008) - desenvolvido pela psicanalista Esther Bick, em 1948, na Clínica Tavistock, Londres. Considerada parte da formação em Psicanálise e na Educação, a observação Bick tem sido crescentemente utilizada na pesquisa, em conjunto com a aplicação clínica e o potencial como fonte de conhecimento teórico e de geração de novas hipóteses (Rhode, 2004; Rustin, 2009).

Bick almejava a objetividade científica na observação e o uso da experiência subjetiva na compreensão dos dados, refinando a capacidade para perceber as realidades psíquicas primitivas (Souza, 2008). A afetação do observador é aspecto central na técnica: sua mera presença produz efeitos no campo observado, e a qualidade da observação depende da sua maturidade psíquica, teórica e técnica. Ao incluir o observador no campo emocional, Bick deslocou a Psicanálise das ciências explicativas (Mélega, 2001), legitimando o singular na produção do conhecimento por meio das relações entre o teoricamente posto, o empiricamente observado e o subjetivamente apreendido.

O método Bick sintetiza os princípios científicos da Psicanálise que permitem a investigação, norteiam a clínica e fundamentam a teoria. Apesar da sua simplicidade, que inclui três momentos - observação no ambiente natural, escrita posterior e supervisão -, é complexa a tarefa de criar e manter o setting de observação, o qual cria um ambiente adequado para que os processos psíquicos se manifestem e para que o inesperado ocorra (Lisondo, 2003). Trata-se de um exercício de escuta sucessiva, em níveis diferentes, do mais regressivo ao mais elaborado, caracterizando-o na contramão da irreflexão e do subjetivismo (Caron, Lopes, Steibel, \& Donelli, 2012; Lisondo, 2003).

Nos moldes originais, o momento de observação é desenvolvido na casa do bebê, com duração de uma hora, uma vez por semana, do seu nascimento aos dois anos. Observa-se o desenrolar das relações mãe-bebê-família, mediante postura de abstinência, não intrusiva, não crítica, sob atenção flutuante. Essa atitude estimula a mãe a encontrar seu jeito próprio de entender e lidar com as necessidades do bebê, ao mesmo tempo em que implica o observador numa receptividade psíquica, potencializando o processo transferencial. Este recebe, com sua afetividade, sua fantasia e seu corpo, as "comunicações" positivas e negativas, captando estados emocionais primitivos que devem ser transformados psiquicamente (Bick, 1964).

O segundo momento - a escrita - acontece logo após a observação, registrando detalhadamente o que se recorda e os afetos experimentados. Essa meticulosidade implica no cuidado de não deduzir os sentimentos do bebê rapidamente, evitando perder a "evidência" na qual a interpretação se baseará; os registros podem enriquecer ou distorcer o material, ficando sujeitos à análise cuidadosa (Bick, 1964). As angústias e ansiedades vividas na transferência são analisadas na supervisão - terceiro tempo -, focando o que foi observado e o instrumento de observação (o observador e as projeções introjetadas). A reflexão e a elaboração cognitiva dão sentido às vivências e projeções, preservando a função do observador, para que sua participação psíquica intensa não inviabilize a construção de pressupostos e o setting, fornecendo suporte ético, no uso positivo dos fenômenos transferenciais (Rustin, 2009).

Deve-se adotar atitude de espera, tolerância e paciência, aguardando que sentidos surjam da regularidade do acompanhamento, mediante a singularidade de cada relação, observando a emergência de padrões interacionais (Bick, 1964). Nos moldes clássicos, não é desenvolvida intervenção interpretativa nas observações, pois o objetivo é compreender aspectos do fenômeno transferencial, diferente da técnica na clínica, que modifica o curso das motivações inconscientes na transferência. No método Bick, a meta não é terapêutica, apesar da implicação de poder sê-la; o observador deve renunciar ao furor curandi (Lisondo, 2003).

Em virtude da qualidade e da possibilidade de ressonância positiva nos envolvidos, esse método se expandiu, desdobrando-se numa variação de settings e aplicações na formação, na clínica e na pesquisa (Rhode, 2004). Os conceitos advindos dessa técnica remetem ao entrelaçamento de método e teoria (Rustin, 2009), sustentando que o trabalho de pesquisa é intrínseco à experiência clínica (Lowenkron, 2004).

Em 1997, foi criado o International Journal of Infant Observation and its Applications, com publicações teórico-práticas sobre o método Bick. O primeiro artigo publicado no Brasil sobre o Bick foi o de Farias e Tucherman (1988), discorrendo também sobre a formação analítica. A sétima conferência internacional (2014) - Teaching infant observation and thinking about wider applications of the method-abordou a pesquisa qualitativa e o Bick. Em 2014, foi criada a Associação Latinoamericana de Observadores de Bebê Método Bick, filiada à Associação Internacional para o Desenvolvimento da Observação de Bebês Método Bick.

A contribuição do Bick à pesquisa é reconhecida na compreensão do desenvolvimento emocional de indivíduos e grupos e na interlocução com ciências que almejam incorporar a experiência subjetiva e intersubjetiva do pesquisador (Urwin \& Sternberg, 2012). Entretanto, mais pode ser feito quando a pesquisa é o seu principal objetivo (Rustin, 2012); aponta-se o potencial do Bick para se expandir no meio acadêmico brasileiro (Oliveira-Menogotto, Menezes, Caron, \& Lopes, 2006), não apenas com bebês, mas também com adultos (Santos \& Pedroso, 2017) e idosos.

Questiona-se como o Bick é retratado nas publicações brasileiras, bem como as possibilidades de adaptação e utilização deste no reconhecimento das experiências intersubjetivas dos sujeitos. Este artigo remete a uma revisão sistemática da produção brasileira sobre o método Bick de observação, buscando identificar e discutir suas possibilidades de desenvolvimento, do uso no ensino à aplicação na pesquisa acadêmica, analisando tendências e tensões. 


\section{MÉTODO}

Desenvolveu-se uma revisão sistemática da literatura acerca da produção científica brasileira sobre o método Bick, mediante levantamento de publicações em bases de dados nacionais (SciElo, Biblioteca Virtual em Saúde [BVS] e Portal Periódicos da Coordenação de Aperfeiçoamento de Pessoal de Nível Superior [CAPES]). A avaliação crítica do material já publicado buscou compreender a finalidade do trabalho e as nuances na aplicação do método. As bases de dados foram acessadas em novembro e dezembro de 2014.

A fim de refinar a busca e assegurar o direcionamento para as publicações relevantes aos objetivos, foram pesquisados os Descritores em Ciências da Saúde (DeCS) relativos ao método de observação Esther Bick, também conhecido por Observação da Relação Mãe-Bebê. Como não há referência a esse tipo de observação como um descritor, foram utilizados os termos livres observação e Bick; observação Bick; método e Bick; observação, Bick e relação mãe-bebê, Esther e Bick, que constavam no título, resumo e/ou palavras-chave, testando-se diferentes estratégias de busca nas bases de dados.

Foram considerados elegíveis os trabalhos publicados em revistas brasileiras nas línguas Português, Inglês e Espanhol, sem restrição ao período de publicação, nos quais foi apresentado desenvolvimento teórico e/ou prático sobre o método Bick de observação. Como critério de exclusão, foram descartados os que não referissem a aplicação do Bick no Brasil, bem como os que não remeteram especificamente a esse tipo de observação (teórica ou empiricamente). $\mathrm{Na}$ seleção dos trabalhos, foram seguidas quatro etapas: (1) seleção pelo título; (2) seleção pelo resumo; (3) leitura do trabalho na íntegra; (4) análise crítica do trabalho.

Excluídas as repetições, foram selecionados 42 trabalhos, descartando-se oito, totalizando 34 considerados válidos (indicados nas referências com *). Em dois casos, os artigos remetiam à mesma pesquisa (Golin \& Donelli, 2011 e Golin \& Benetti, 2013; OliveiraMenegotto \& Lopes, 2009 e Oliveira-Menegotto, Lopes, \& Caron, 2010), mantidos por focarem aspectos teóricos e resultados diferentes. $\mathrm{Na}$ análise, foram abordados: (a) ontexto da publicação (origem, ano e acesso), instituição de proveniência do trabalho (pública, privada), formato (artigo, dissertação, tese) e natureza (trabalho teórico ou prático); (b) Tema e embasamento teórico; (c) Análise dos recursos metodológicos, para os trabalhos de natureza prática (objetivos, técnicas/instrumentos, sistemática na construção dos dados e análise).

\section{RESULTADOS E DISCUSSÃO}

\section{Contexto da Publicação}

A seleção dos 34 trabalhos identificou 25 em formato de artigo, sete dissertações e duas teses. Dentre os artigos, 12 têm acesso livre on-line. É possível que existam trabalhos com o tema pesquisado que ainda não tenham sido publicados em periódicos indexados ou incluídos no Portal de Periódicos CAPES. Outras produções, como livros, são comuns em Psicologia e principalmente em Psicanálise. Essa é uma limitação da presente pesquisa.

Dos 25 artigos, 11 advêm da academia. Três destes foram desenvolvidos em cursos de graduação, em São Paulo (SP) e no Rio Grande do Sul (RS), uma publicação foi fruto de pesquisa de PIBIC (Programa Institucional de Bolsas de Iniciação Científica), desenvolvida em SP, duas remetem à mesma pesquisa de mestrado (RS), quatro artigos são oriundos de três teses (duas no RS, uma em Pernambuco - PE) e um foi fruto de projeto de pós-doutorado (Bahia). Dois artigos não informaram associação com evento e/ou curso (os autores são do RS e de SP). Três deles remontam a observações desenvolvidas em curso de especialização e/ ou formação no método Bick (dois no RS, um em SP). Nove artigos remetem a apresentação oral em congresso, jornada, colóquio ou simpósio (cinco autores do RS e quatro de SP).

A maior parte dos trabalhos foi publicada entre 2001 e 2010 (48\% dos artigos e aproximadamente $72 \%$ das dissertações). Nenhuma tese foi identificada nesse período; em relação à dissertações, uma foi identificada. Doze artigos advêm de trabalhos acadêmicos (cinco de graduação, uma dissertação, três teses e um pós-doutorado), seis publicados entre 2011-2014, cinco entre 2001-2010 e apenas um em 1999. Somando as dissertações, teses e artigos advindos dessas, ao todo 21 trabalhos estão ligados à academia. Talvez o fato de poucas dissertações e teses estarem publicadas entre 2011-2014 esteja associado à modificação na política dos cursos de pós-graduação, solicitando cada vez mais a produção em formato de artigos.

São 17 as revistas nas quais estão os 25 artigos. As regiões Sudeste (com oito revistas e 14 publicações) e Sul (seis revistas e oito publicações) tiveram maior incidência de revistas e de publicações, com apenas três revistas de outras regiões (duas revistas e duas publicações do CentroOeste; uma revista e uma publicação do Nordeste). Onze revistas (quase 65\%) são ligadas a instituições de ensino e pesquisa acadêmica em Psicologia/Psicanálise (graduação e/ou pós-graduação), todas no Sul, Sudeste e Centro-Oeste.

Quanto às instituições ligadas aos autores, duas estão no Nordeste: Universidade Federal da Bahia (UFBA) e Instituto de Medicina Integral Prof. Fernando Figueira (IMIP), PE. Os demais onze trabalhos estão vinculados a instituições no RS (dois), em SP (nove) e no Rio de Janeiro - RJ (um). Onze trabalhos não foram associados a nenhuma instituição, 
no entanto, seus autores são todos dos estados de SP (seis) e do RS (cinco).

Dez instituições são privadas, cinco públicas e uma filantrópica. Apesar da maior incidência de instituições privadas, o número de trabalhos foi praticamente o mesmo (doze de privadas e onze de públicas). Das instituições privadas $(\mathrm{n}=10)$, com 12 trabalhos, todas são do RS (Universidade do Vale dos Sinos [UNISINOS], Universidade Luterana do Brasil [ULBRA], Pontifícia Universidade Católica do RS, Hospital Ernesto Dornelles, Centro de Estudos Luís Guedes, Centro de Estudos, Atendimento e Pesquisa da Infância e Adolescência - CEAPIA) e de SP (Centro de Estudos Psicanalíticos Mãe-Bebê-Família, Universidade de São Marcos, Pontifícia Universidade Católica de São Paulo [PUCSP], Universidade Metodista de $\mathrm{SP})$. Das instituições públicas $(\mathrm{n}=5)$, com 11 trabalhos, duas são de SP (Universidade de São Paulo - USP, Universidade Estadual de Campinas), uma do RJ (Fundação Oswaldo Cruz), uma do RS (Universidade Federal do RS) e uma da Bahia (UFBA).

Em todos esses aspectos apontados (revistas, instituições de origem dos trabalhos e região dos autores), houve predominância quase absoluta das regiões Sul e Sudeste. Talvez isso se explique pelo fato de que as instituições que têm utilizado o Bick na educação profissional em diferentes modalidades curriculares (graduação, pós-graduação e formação), no auxílio ao trabalho clínico e/ou de pesquisa, estão situadas em sua esmagadora maioria nas regiões citadas.

Das instituições que oferecem treinamento no Bick, duas estão no RJ, quatro em SP, seis no RS, uma em Goiânia, uma em Brasília e uma em Belo Horizonte. Três novos grupos estão em constituição, todos no Sul. São apontados 54 profissionais responsáveis pela formação com o Bick: 27 no Sul, 23 no Sudeste, três no Centro-Oeste e um no Nordeste. Dos 21 grupos de observação Bick no Brasil, 57\% $(12 / 21)$ o aplicam na clínica e $15 \%$ na universidade (Caron \& Lopes, no prelo).

Quanto à natureza dos trabalhos (Tabela 1), foram classificados como teóricos - pesquisa de caráter histórico e conceitual ( $\mathrm{n}=13,11$ artigos e duas dissertações) - ou práticos $(\mathrm{n}=18,14$ artigos, quatro dissertações e uma tese). Os trabalhos práticos são: (a) advindos da clínica ou da formação, não acadêmicos $(\mathrm{n}=3)$; (b) advindos da prática acadêmica, envolvendo pesquisa de campo com o Bick e/ou outra técnica/instrumento $(\mathrm{n}=15)$. Três foram classificados como outros (dois artigos, uma dissertação e uma tese), de natureza prática, porém sem o Bick no campo empírico. Houve predominância de trabalhos de natureza prática, principalmente os oriundos de pesquisa acadêmica, o que sugere disseminação do Bick nesse contexto. Segundo Loureiro (2002), parte expressiva das publicações brasileiras em Psicanálise é realizada em universidade. Entretanto, o Bick pode se expandir no meio acadêmico, pois, segundo Caron e Lopes (no prelo), apenas três grupos o aplicam na universidade.

A maioria dos trabalhos teóricos inclui vinhetas de observações ilustrando conceitos e/ou reflexões práticas. Alguns refletem sobre ou apresentam adaptações e/ou acréscimos ao Bick no ensino e na clínica, apontando o potencial na prevenção, no diagnóstico e no tratamento,

Tabela 1.

Classificação dos trabalhos segundo a natureza (ordem cronológica decrescente)

\begin{tabular}{|c|c|c|}
\hline \multicolumn{3}{|c|}{ Natureza do trabalho } \\
\hline Pesquisa teórica sobre o Método Bick & $\begin{array}{l}\text { Pesquisa prática com uso do Bick e/ou outra } \\
\text { técnica/instrumento associado }\end{array}$ & $\begin{array}{l}\text { Outro (pesquisas práticas, porém sem uso } \\
\text { Bick como instrumento ou técnica na } \\
\text { construção do campo) }\end{array}$ \\
\hline $\begin{array}{l}\mathrm{n}=13 \\
\text { Sampaio, Falbo, Feliciano, } \\
\text { Camarotti, Rustin, \& Miller, 2012; } \\
\text { Escosteguy, 2012; } \\
\text { Steibel, 2011; } \\
\text { Oliveira-Menegotto, Menezes, } \\
\text { Caron, \& Lopes, 2006; } \\
\text { Amorim, 2004; } \\
\text { Stocche, 2003; } \\
\text { Maltz, 2003; } \\
\text { Mélega, 2001; } \\
\text { Costa, 2000; } \\
\text { Falcão, 1999; } \\
\text { Guimarães, 1998; } \\
\text { Mélega, 1997; } \\
\text { Caron, 1995. }\end{array}$ & $\begin{array}{l}\mathrm{n}=18 \\
\text { Oriundos da prática clínica ou de formação } \\
\text { (não acadêmicos) n=3: } \\
\text { Laks, Filipouski, Germani. \& Valente, 2009; } \\
\text { Grillo, 2006; } \\
\text { Araújo, 2004; } \\
\text { Oriundos da prática acadêmica n=15: } \\
\text { Bustamante \& McCallum, 2014; } \\
\text { Golin \& Benetti, 2013; } \\
\text { Donelli \& Lopes, 2013; } \\
\text { Santos, 2012; } \\
\text { Golin, Benetti, \& Donelli, 2011; } \\
\text { Oliveira-Menegotto, Lopes, \& Caron, 2010; } \\
\text { Oliveira-Menegotto, \& Lopes, 2009; } \\
\text { Pergher \& Cardoso, 2008; } \\
\text { Souza, 2008; } \\
\text { Stoiani, 2007; } \\
\text { Tavares, 2007; } \\
\text { Freitas \& Ângulo, 2006; } \\
\text { Vivian, 2006; } \\
\text { Siqueira \& Andriatte, 2001; } \\
\text { Appio \& Matte, 1999. }\end{array}$ & $\begin{array}{l}\mathrm{n}=3 \\
\text { Scorsolini-Comin, Nedel, \& Santos, 2011'; } \\
\text { Corte, } 2005^{2} \text {; } \\
\text { Casseb, } 1993^{3} \text {. } \\
{ }^{1} \text { Relato de experiência sobre o uso no Bick na } \\
\text { formação do psicólogo como observador da } \\
\text { relação mãe-bebê-família. } \\
{ }^{2} \text { Compreensão sobre a utilização do Bick na } \\
\text { aquisição de capacidades psicoterapêuticas. } \\
{ }^{3} \text { Aplicação do Método Observacional- } \\
\text { Compreensivo, composto parcialmente pelo } \\
\text { Método de Observação da relação mãe-bebê na } \\
\text { família e pela aproximação compreensiva do } \\
\text { Método Clínico. }\end{array}$ \\
\hline
\end{tabular}


porém resguardando a origem e a identidade epistemológica do método. Caron (1995) apresenta o observador Bick como consultor no hospital, creche e escola. Escosteguy (2012) vem ampliando o Bick em aplicações preventivas e terapêuticas, com filmagens a cada trimestre do bebê, entregando-as à família como modo de despedida do observador. Um relatório final é produzido com o propósito de trabalho científico longitudinal.

Os autores com maior número de produções foram: Lopes, Oliveira-Menegotto, Caron, Donelli, Golin, Benetti e Mélega. Mélega, Caron e Lopes são consideradas autoraschave. Mélega (2008) organizou livro sobre aplicações do Bick em contextos clínicos e não clínicos (na pré-escola, com idosos, em instituição hospitalar e de saúde mental). Caron (2000) organizou livro sobre a aplicação do Bick em diversos contextos, destacando seu caráter preventivo e multiplicador: clínica de ultrassonografia obstétrica, unidade de terapia intensiva neonatal, enfermaria cardiológica pediátrica, creche, no ensino médico.

Outros autores não listados nesta pesquisa utilizam o Bick na avaliação psicanalítica do desenvolvimento infantil, para o diagnóstico precoce de transtornos globais do desenvolvimento e na prevenção de distúrbios emocionais (Lisondo, 2012).

\section{Tema e Embasamento Teórico}

Rustin (2006) identifica que muito já foi produzido no âmbito mundial sobre o Bick, mediante quatro áreas de investigação: (a) o desenvolvimento da psique infantil e da integração corpo e mente; (b) os diferentes padrões de continência emocional e suas falhas; (c) o valor terapêutico da observação psicanalítica, seja nos moldes clássicos ou nas adaptações em que o observador assume postura interventiva; (d) as contribuições na revelação de variações entre culturas com relação ao desenvolvimento psíquico, auxiliando na compreensão do modo como esses padrões variam entre as culturas e a extensão das variações.

$\mathrm{Na}$ presente pesquisa, as áreas "a", "b" e "c" estão representadas em diversos estudos, combinadas ou desenvolvidas de modo independente. Nenhum trabalho destacou explicitamente as variações culturais com relação ao desenvolvimento psíquico, apesar de algumas pesquisas abordarem diferentes dimensões socioculturais envolvidas neste processo.

Bustamante e McCallum (2014) e Vivian (2006) aplicaram o Bick em famílias de baixa renda. Apontam que o potencial estimulador do ambiente não está centrado apenas na renda familiar, sendo fundamental considerar os múltiplos fatores envolvidos no desenvolvimento infantil, bem como a influência da família e da sociedade nas práticas de cuidado. Sampaio et al. (2012) desenvolveram observações Bick em contexto cultural diferente daquele da observadora - como parte de intercâmbio acadêmico na clínica Tavistock - e da mãe da criança observada (esta de origem não inglesa, residindo em Londres). Apesar dos aspectos culturais não terem sido centrais, a língua nativa da mãe e da observadora tiveram papel importante no modo como a mãe e a criança se comunicavam na intimidade e na construção dos significados às observações. A língua refere, além do uso social, às crenças e pressupostos inconscientes que constituem a cultura e são projetados e introjetados. O Bick facilitou a compreensão de que a psique pode ser apreendida para além de línguas e culturas.

No Brasil, segundo Corte (2005), as publicações sobre o método Bick podem ser incluídas nas seguintes categorias: divulgação do método, fragmentos de observação da relação mãe-bebê, intervenção e formação de psicoterapeutas. Em consonância com Rustin (2006) e Corte (2005), os trabalhos identificados nesta pesquisa foram agrupados em cinco categorias: Aspectos teórico-práticos do Bick - 12 trabalhos; Relação mãe-bebê - sete trabalhos, que, apesar de terem como foco a relação mãe-bebê, situaram a díade no contexto da família: relação família-bebê e relação pais-filho(s); Relação família-profissionais de saúde - seis trabalhos: família-bebê-profissionais de saúde; criança institucionalizada-cuidador; mulher-equipe hospitalar; mãe-bebê/família-equipe médica; comunicação mãe-bebêprofissionais de Equipe de Saúde da Família; Processos operantes e a formação do observador Bick - quatro trabalhos: papel e formação do observador; capacidades que o psicoterapeuta pode desenvolver com o método; Diferentes aplicações e possibilidades do Bick, incluindo a pesquisa - cinco trabalhos: Bick como instrumento à prática médica; potencial do Bick como método de pesquisa; aproximações entre o Bick e a pesquisa qualitativa.

Quanto ao referencial teórico, havia a expectativa de que a Psicanálise tivesse sido utilizada em todos os trabalhos, devido aos aspectos epistemológicos que caracterizam o Bick. Entretanto, apesar da quase absoluta representatividade do referencial psicanalítico, Bustamante e McCallum (2014) analisaram, sob a hermenêutico-dialética, a organização sociocultural do cuidado na constituição e transformação das práticas alimentares. Mesmo considerando que o processo de construção do ser ocorre mediante projetos nem sempre enunciados discursivamente, expressos por meio do corpo, estima-se que esses aspectos não foram tratados segundo compreensão psicanalítica. Nos resultados, não se percebe implicação afetiva do observador, sem indícios de interpretação advinda de suas formações imaginárias. A compreensão intersubjetiva considerada nessa pesquisa talvez tenha vindo da análise das ações sociais, não dos aspectos intersubjetivos inconscientes.

$\mathrm{O}$ uso de referencial alternativo à compreensão do material advindo do Bick esteve também em ScorsoliniComin, Nedel e Santos (2011), com a perspectiva fenomenológica (Dartigues) para compreender o processo de formação do observador. Sampaio et al. (2012) abordaram os processos envolvidos na comunicação entre profissionais da Estratégia de Saúde da Família e mães-bebês sobre 
amamentação, mediante a Psicanálise a Hermenêuticodialética, num diálogo entre a observação antropológica e a psicanalítica (método Bick).

Os demais trabalhos adotaram conceitos e/ou construtos da Psicanálise e/ou Psicologia: Klein, Bion, Winnicott, com conceitos de Bick, Harris, Mahler, Meltzer, Balint, Mannoni, Dolto, Ogden, Cramer, Soulé, Lebovici, Soifer, Bowlby, Ainsworth. Estima-se que a complexa e vasta experiência criada pelo Bick pode ser aprofundada por meio de referenciais teóricos alternativos que contribuam ao aprofundamento e teorização dos fenômenos.

\section{Análise dos Recursos Metodológicos}

Foram identificados 21 trabalhos de natureza empírica, dos quais 15 remetem à prática acadêmica. Apesar de Scorsolini-Comin et al. (2011), Corte (2005) e Casseb (1993) apresentarem descrição do método empregado no trabalho de campo, não utilizaram a observação Bick como instrumento ou técnica de pesquisa.

Corte (2005) apresenta contribuições empíricas à discussão sobre o Bick como auxiliar na aquisição de capacidades psicoterapêuticas. $\mathrm{O}$ autor utilizou o método qualitativo, com entrevistas semidirigidas, analisadas segundo a técnica de análise de conteúdo. Apesar de o escopo remeter às contribuições para a atividade psicoterápica, estima-se que a ampliação da percepção dos sentidos do observador (ampliação da escuta, da continência, do lidar com o não-saber e da capacidade de relacionamento) pode ser considerada importante contribuição ao profissional de qualquer formação atuando na clínica e/ou na pesquisa empírica. Essa técnica instrumentaliza não só no nível profissional, como também no nível pessoal, aqueles que precisam continuamente desenvolver e refinar habilidades reflexivas e interpessoais.

Scorsolini-Comin et al. (2011) abordaram o potencial do Bick à vivência do observador em formação. Consideraram esse um instrumento que expande as potencialidades do futuro profissional ao ampliar a capacidade de continência do estagiário em situações de intenso impacto psíquico, auxiliando na compreensão do seu papel e na identificação e superação de obstáculos. Pergher e Cardoso (2008), com objetivo de compreender o papel do observador, o reconhecem como um instrumento que ajuda a expandir as potencialidades do analista no lidar com aspectos primitivos e psicóticos, ampliando a capacidade de continência.

Casseb (1993), abordando a relação médico-paciente com o Método Observacional-Compreensivo, composto parcialmente pelo Bick, aponta este como proposta efetiva ao desenvolvimento das funções de continência do observador. A aproximação do fenômeno psíquico a partir da experiência observacional, aparelhando o pesquisador no envolvimento emocional no campo, aponta para a contratransferência na prática clínica. "Não propomos uma aproximação 'ipis litteris' do método de observação de bebês, mas a possibilidade observacional que o médico pode desenvolver (...) focalizando o campo emocional" ( $p$. 58). "Ao invés de responsabilizar a mãe, ou a sociedade, ou o sistema, o médico poderá dispor de um equipamento de ajuda no sentido de construir um ambiente mais facilitador para o desenvolvimento do seu paciente" (p. 156). Falcão (1999) também refletiu sobre a relação médico-paciente, aplicando o Bick em Residência médica, propondo-o como instrumento de trabalho ao pediatra.

São discutidos a seguir aspectos metodológicos das 13 pesquisas (gerando 15 trabalhos) que aplicaram a observação Bick como técnica no campo ou que utilizaram observações previamente realizadas como material secundário num projeto acadêmico desenvolvido posteriormente, permitindo uma análise no sentido da pesquisa acadêmica - contexto, técnicas empregadas, sistemática na construção dos significados e análise destes. As publicações de Golin e Benetti (2013) e Golin, Benetti e Donelli (2011), bem como as de Oliveira-Menegotto et al. (2010) e Oliveira-Menegotto, Menezes, Caron e Lopes (2006), remetem à mesma pesquisa, conjugando nesta análise suas informações metodológicas.

Diferente do espaço disponível numa dissertação e tese clássicas, num artigo tem-se a redução no número de palavras exigido pelas revistas, que talvez tenha limitado as informações sobre o método. Foram frequentes lacunas quanto à sistemática das observações, formato da supervisão, preparo do observador e análise, dentre outras informações.

Repetiu-se a predominância do eixo Sudeste-Sul. Cinco trabalhos vieram de cinco cursos em SP: dois de mestrado na USP e um na PUC, um de doutorado na USP, um curso de graduação na Universidade Metodista de SP. Sete trabalhos vieram de cinco cursos situados no RS: um de mestrado na UNISINOS (com dois trabalhos publicados), dois de doutorado na UFRS (com três trabalhos publicados) e um de graduação na ULBRA. Uma pesquisa adveio de pós-doutorado na UFBA. Dois trabalhos não apresentavam referência a instituições, mas estima-se terem sido desenvolvidos por alunos de graduação em SP.

Santos e Pedroso (2017) desenvolveram uma revisão, analisando a produção científica brasileira sobre adaptações do método Bick em pesquisas empíricas (recorte temporal de 2000-2015). Com base em seis artigos, identificaram que as adaptações envolveram a quantidade de sessões, idade dos participantes (bebês, crianças e adultos), a transcrição e a supervisão. Todas as pesquisas obedeceram às três fases do método, conseguindo captar informação subjetiva em situações nas quais a fala dos participantes era inacessível.

No que concerne às adaptações observadas em nossa revisão, cinco trabalhos foram realizados em instituições: dois em abrigos para crianças e três em hospitais (mulheres e equipe em centro obstétrico; mulheres em sala de parto e enfermaria; pais, bebês e equipe em Unidade de Terapia Intensiva Neonatal e Pediátrica [UTINP]). As demais pesquisas envolveram bebês e suas famílias, observados nas residências: duas famílias de baixa renda; um bebê com 
Síndrome de Down e seus pais; um bebê, sua mãe e avó; uma família (mãe, pai, bebê e irmão); uma díade mãe-bebê (mãe em luto); uma família numerosa (pai, mãe, bebê e três irmãos); cinco pares de gêmeos e seus cuidadores.

Quanto ao tempo em campo, as pesquisas mais breves envolveram: cinco observações (Freitas \& Ângulo, 2006); 15 observações (Golin et al., 2011; Golin \& Benetti, 2013); 16 observações (Siqueira \& Andriatte, 2001). Bustamante e McCallum (2014) e Stoiani (2007) observaram do primeiro ao $12^{\circ}$ mês das crianças, porém não especificaram a frequência e a duração das observações. Pergher e Cardoso (2008) estenderam a observação até o $18^{\circ}$ mês infantil, sem especificar a frequência e a duração. Souza (2008) não mencionou o número de observações, nem a quantidade de famílias observadas, mas relatou que estas foram realizadas ao longo de um ano, modificando a frequência de uma para duas vezes por semana. Os demais trabalhos envolvendo bebês e família abrangeram entre 39 e 79 observações semanais e/ou quinzenais (após o primeiro ano), do nascimento ao $12^{\circ}$ mês.

O formato mais comum da supervisão foi o grupal (em seis trabalhos), com frequência semanal (em três trabalhos); dois não informaram se desenvolveram supervisão. Um pesquisador relatou não ter desenvolvido supervisão, apontando que coletou os dados ao longo de cinco anos, o que acarretaria alto custo financeiro. Vivian (2006) informou supervisão semanal por cinco meses, que nos últimos sete meses passou a ser mensal. Caron e Lopes (no prelo) apontam em seu mapeamento que em $76 \%$ dos casos (16/21) a supervisão é semanal; nenhum grupo via Skype - ferramenta utilizada em outros países, na formação e na pesquisa (Urwin \& Sternberg, 2012). Percebe-se, como apontado por Oliveira-Menegotto et al. (2006), uma variedade de aplicações, com modificações no local, quantidade, frequência, duração das observações, na supervisão e quanto aos participantes.

Na condução das observações, Souza (2008) menciona um grupo de observadores treinados e coordenados por ela (pesquisadora principal, com experiência no método), mas os casos discutidos foram observados e acompanhados por esta, mediante a técnica Intervenções Terapêuticas Conjuntas na UTINP (foco da pesquisa). Em Bustamante e McCallum (2014), as observações foram realizadas por duas pesquisadoras (alunas de graduação). Três trabalhos não mencionam o número de observadores e os demais contaram com apenas um observador.

Autores como Mélega (2001) defendem a importância de o observador Bick passar por treinamento. Seis pesquisas referem que o observador tinha treinamento prévio ou estava em formação. Lisondo (2007) destaca que a formação do observador e sua equação pessoal podem auxiliá-lo na ampliação dos horizontes de pensabilidade ante o bombardeio sensorial, mental e institucional, advindos da aplicação do Bick. Safra (1993) enfatiza a importância de o pesquisador estar em análise, promovendo um espaço de investigação diferenciado dos processos pessoais em campo, em especial quando a investigação parte do material clínico. Duas pesquisas mencionaram o fato de o observador estar em análise ao longo do processo de observação: "situações aflitivas e angustiantes são vivenciadas intensamente durante as observações, (...) o trabalho analítico torna-se pré-requisito" (Freitas \& Ângulo, 2006, p. 89).

Estima-se que os trabalhos de Santos (2012) e Pergher e Cardoso (2008) tenham sido desenvolvidos mediante observações previamente realizadas, talvez no contexto de formação, não de pesquisa acadêmica. Esse foi o caso de Stoiani (2007), que utilizou transcrições de observações como material secundário no mestrado. Tavares (2007) não deixa claro em que contexto as observações foram construídas, pois foram realizadas ao longo de cinco anos, tempo superior ao de um doutorado (quatro anos). Rustin (2012) defende o uso em pesquisa acadêmica do material construído em observações previamente realizadas, citando exemplos bem-sucedidos, identificando no a posteriori aspectos imprevistos e novos significados.

Bick (1964) preconizou o uso da atenção flutuante nos três momentos, não estabelecendo um foco a priori. Estima-se que haja diferenças na observação realizada sem fins acadêmicos e na observação como técnica de pesquisa acadêmica, com um foco direcionado, em parte, aos objetivos previamente estipulados no projeto. No trabalho acadêmico existe a prerrogativa de um objetivo, com possíveis repercussões na atenção flutuante e na transferência. Recomendamos que o fundamento da postura defendida por Bick seja perseguido pelo observador acadêmico ao delimitar objetivos e pressupostos meramente norteadores, sem impedir a criação do espaço psíquico, com um mínimo de a priori, para ver o que precisa ser visto e não olhar para o que se pensa poder encontrar (Costa, 2000). No enquadre da observação psicanalítica, a única intencionalidade possível é a do inconsciente, e não de hipóteses predeterminadas (Lowenkron, 2004).

Stoiani (2007) defende que a postura do observador deve ser de "implicação reservada": colocar o corpo e mente à disposição da experiência, mas em reserva a fim de preservar um espaço para pensar sobre o vivido. Esse "pensar depois" acontece quando se proporciona (na escrita) e se submete (na supervisão) a um contato diferente com o material observado. Já não é o destinatário das projeções vindas da observação; pode tornar-se seu agente ativo, liberando-as (Caron et al., 2012). Deverá compreender e reencontrar seu lugar como observador, sem atuar um papel dentre aqueles que lhe podem ser oferecidos consciente ou inconscientemente (Bick, 1964) - isso é o que mantém o setting observacional, sem o qual não há pesquisa possível.

Quanto às possíveis alterações no âmbito da transferência, o Bick aplicado na academia envolve um universo maior de alteridades com as quais o observador desenvolve transferência, ressonando nos momentos da observação à escrita do material. Estão envolvidos a mãe e seu bebê, o 
observador e a díade (e com cada um desta), o observador e o grupo de supervisão, o observador e o ambiente da academia (a quem dirige a escrita). Se a escrita em Psicanálise implica o pesquisador no modo como se relaciona com esses lugares de alteridade, na academia tem-se a comunidade científica, da banca às revistas. Como apontado por (Oliveira, 2011), "a escrita em Psicanálise não é coerente com o modelo positivista de ciência ou com a escrita desafetada, impessoal e neutra geralmente presente na academia" (p. 28), pelo contrário, deixa a marca da implicação do autor (Queiroz, 2005). É interessante destacar outra particularidade do Bick aplicado na academia, explorada de modo original por um grupo do RS (Caron et al., 2012). Além da observação, do relato e da supervisão, o grupo desenvolve um quarto momento, destinado à publicação científica do material. Essa estratégia foi adotada por Donelli e Lopes (2013) e Vivian (2006). Nesse quarto momento, o material é traduzido em linguagem dirigida a um público maior e desconhecido. São destacados os principais aspectos supervisionados, revisitando pressupostos, discussões e interpretações, numa percepção da experiência em nível mais integrado. Tenta-se criar no leitor as principais experiências emocionais do processo, compartilhando conclusões teórico-práticas.

$\mathrm{O}$ grupo do RS aponta que a escrita destinada à publicação requer equilíbrio, podendo correr o risco de ceder às exigências acadêmicas, tornando-se excessivamente conclusiva e objetiva, eliminando a riqueza e o potencial para gerar novas formulações. Por outro lado, corre o risco de ceder à tentação de revelar com muitos detalhes a experiência intensa, expandindo excessivamente o material, tornando-o incompreensível (Lopes, Caron, Steibel, \& Donelli, 2012). Se tomada como estratégia de análise acadêmica, a escrita auxilia na construção de eixos norteadores, definidos a partir dos padrões que tendem a se repetir nas observações e/ou de suas singularidades (Vivian, 2006). Em termos de controle de qualidade, talvez o quarto momento funcione como apoio ao observador, fornecendo estrutura e distância nas elaborações cognitivas, mais uma fonte de análise e triangulação entre pesquisadores.

Vivian (2006) desenvolveu um "estudo de caso único, longitudinal, de caráter qualitativo", referenciando Stake (1994) e Yin (2005), que tratam o estudo de caso não como uma metodologia, mas como uma escolha de objeto e uma estratégia de pesquisa. Donelli e Lopes (2013) identificam um "estudo de caso único com aplicação do Bick para fins de pesquisa", acompanhando 112 mulheres e a equipe de assistência (médicos, enfermeiros, técnicos de enfermagem, estagiários e pessoal de apoio) num centro de obstetrícia (tomado como "caso"), com observações semanais, de duas horas de duração, no mesmo dia e horário.

Appio e Matte (1999) realizaram uma "pesquisa qualitativa, estudo exploratório-descritivo combinado (...); um estudo de caso qualitativo, (...) que pretendeu aprofundar um único caso" (p. 55), referenciando Stake (1994). Oliveira-Menegotto et al. (2010) / Oliveira-Menegotto et al. (2006) e Santos (2012) fazem menção a "um caso", porém sem referenciar um autor. Souza (2008) apresenta sete "casos clínicos".

Diversos são os estilos no uso de fragmentos clínicos que se prestam a funções variadas segundo a estratégia metodológica, a qual, por sua vez, traz implicações diferenciadas ao trabalho produzido (Oliveira, 2011; Queiroz, 2002). No que concerne às pesquisas acadêmicas no campo da Psicanálise, Oliveira (2011) destaca duas estratégias: o estudo de caso (frequentemente utilizado por outras áreas da ciência) e a construção do caso (mais característica do trabalho psicanalítico, pois remonta à clínica reconstruída na supervisão que constrói o caso, e não uma teoria ou clínica cronológica a ser ilustrada). Queiroz (2002) situa que a construção do caso envolve a elaboração de uma hipótese metapsicológica advinda da singularidade da experiência na vivência do pathos, experiência essa que produz uma terceira subjetividade, uma organização ficcional que adquire valor de verdade. O relato desenvolvido não se reduz à experiência em si ou à teoria nele envolvida, remete a uma ficção marcada pela transferência cujos personagens são sustentados por eventos e pessoas reais (Queiroz, 2005).

Poder-se-ia aproximar aspectos da experiência do Bick ao estilo apresentado por Queiroz (2002) na construção do caso. A narrativa do Bick remete não só à cronologia do desenvolvimento do bebê em interação, mas à implicação do observador nessa interação e em sua escrita, bem como na escuta e na escrita da supervisão. Desenvolve-se uma fronteira entre a vivência e a especulação, perpassada pelo inaudível, pela reflexão sobre a transferência e sobre as formações imaginárias do observador partilhadas com outros (grupo de supervisão, academia), revelando uma narrativa fruto do a posteriori, próxima da organização ficcional, ancorada no mundo subjetivo-intersubjetivo, nos eventos e sujeitos reais.

Rustin (2012) situa que as descobertas advindas do Bick são equivalentes aos estudos de casos psicanalíticos, em seu potencial de gerar conhecimento e influenciar a teoria. Destaca a possibilidade de cotejar resultados da observação com pesquisas realizadas com outras metodologias, pois nenhum método é suficiente para estudar um determinado objeto. Segundo Reid (1997), o material advindo do estudo de caso baseado na observação Bick, uma base de dados significativa, geralmente é pouco utilizado e valorizado como instrumento de pesquisa.

Dez pesquisas utilizaram o Bick como única técnica/ instrumento (alguns autores o identificam como técnica, outros como instrumento). Entretanto, não fica claro porque em Bustamante e McCallum (2014) há recortes de longas falas da família que não foram retiradas de notas de campo; também não constam informações relativas a como abordaram a relação entre os usuários e os profissionais de saúde, apesar deste não ser o escopo no artigo; estima-se que ao menos uma técnica tenha sido utilizada junto ao Bick. 
Golin et al. (2011) e Golin e Benetti (2013) aplicaram o Bick, entrevistas com os profissionais (transtorno de apego e não estruturada) e reconstruíram dados da história de vida. Santos (2012), ao concluir as observações Bick, retornou a campo duas vezes, filmando e gravando o último encontro no final do segundo ano da criança, visando os efeitos do ambiente no processo de crescimento e desenvolvimento. Siqueira e Andriatte (2001) aplicaram o Bick "conjugado com o método analítico" (p. 18), sem referência ou explanação quanto a este.

$\mathrm{Na}$ análise, diversas foram as estratégias descritas, mas alguns trabalhos não deixam claro ou sequer mencionam o caminho adotado. Bustamante e McCallum (2014) aplicaram a técnica de análise de conteúdo, considerando a repetição de palavras e o contexto relacional. Appio e Matte (1999) utilizaram a análise de conteúdo e o método das categorias: "um exaustivo processo de organização, separação, contagem e avaliação dos resultados" (p. 56).

Golin et al. (2011) e Golin e Benetti (2013) utilizaram a estratégia de descrição de caso (Yin, 2005), a "técnica analítica de construção da explanação psicodinâmica" e a "técnica de Síntese de Casos Cruzados" (pp. 242-243), sem as explicitar. Siqueira e Andriatte (2001) mencionam a "ficha de interpretação específica", destacando "pontos relevantes para a análise da vida mental do bebê" (p. 8), sem os explicitar. Vivian (2006) abordou relatos da supervisão, definindo três categorias de análise ancoradas na literatura, descrevendo as observações evolutivamente, incluindo uma impressão geral, história familiar e informações fornecidas pela mãe de modo espontâneo. Em Oliveira-Menegotto et al. (2010) e Oliveira-Menegotto et al. (2006), a análise dos fenômenos transferenciais norteou a compreensão psicodinâmica do caso.

Na observação Bick orientada à investigação acadêmica, identificamos, assim como apontado por Rustin (2012), a necessidade de se deixar clara a sistemática na construção dos significados e na análise. Estimamos que, talvez, alguns autores tenham sentido necessidade de identificar o caminho metodológico por meio de construtos advindos dos métodos qualitativos, comumente associados às ciências sociais, assíduos na academia. Como exemplos, estão as aproximações entre o estudo de caso, fazendo par com metodologias alternativas no estabelecimento do caso na pesquisa psicanalítica, como apontado por Iribarry (2003), além das técnicas clássicas de análise de conteúdo e a generalização. Appio e Matte (1999) desenvolveram "um estudo de caso qualitativo, na medida em que pretendeu aprofundar um único caso, e não generalizá-lo para outras situações" (p. 55). Vivian (2006) afirma que seu estudo "é capaz de trazer benefícios especialmente à população com características semelhantes à da família estudada, mas também à sociedade em geral" (p. 39), mas que este não permite generalizações.

Numa investigação sobre a realidade psíquica, o subjetivo e o objetivo são relativizados (Iribarry, 2003; Oliveira, 2011). Remete-se a uma teoria geral da psique e a construtos metapsicológicos generalizáveis, mas não a uma inferência generalizadora para uma amostra ou população, pois o trabalho envolve o significante, não o signo. Os resultados são parte do conjunto de conclusões (provisórias) produzidas pela diversidade de modos como as vivências singulares se inscrevem na totalidade. A singularidade é parte da experiência subjetiva e da intersubjetividade que situa o pesquisador. A abordagem do particular busca compor modelos abrangentes do psiquismo, admitindo que cada sujeito, apesar de compartilhar angústias semelhantes com outros, tem seu psiquismo singularmente estruturado (Safra, 1993).

Talvez a Psicanálise tenha sua parcela de responsabilidade nessa ambiguidade; quiçá ainda paguemos o preço da dicotomia que dificultou o reconhecimento da pesquisa acadêmica com a Psicanálise como representante válida desta. A crença de que há apenas um método de pesquisa na Psicanálise dificulta a reflexão e sua inovação teóricometodológica. Segundo Iribarry (2003), a pesquisa psicanalítica "é sempre uma apropriação do autor que depois de pesquisar o método freudiano descobre um método seu (...) e o singulariza" (p. 03). Esse esforço envolve humildade, habilidade para lidar com a singularidade de cada situação de pesquisa e de cada relação na abertura ao novo. Esse cuidado deve guiar o pesquisador Bick para não transformar o campo numa observação silvestre e superficial dos fatos manifestos; a questão é discriminar as salutares flexibilidade e criatividade da transgressão, zelando pelas condições psíquicas internas e externas para observar o inconsciente (Lisondo, 2007).

\section{CONSIDERAÇÕES FINAIS}

A produção científica brasileira relativa às aplicações do método Bick no ensino, na clínica e na pesquisa acadêmica, identificou predominância quase absoluta das regiões Sul e Sudeste quanto às revistas, instituições associadas aos trabalhos e local de origem dos autores. Predominância também foi observada nos trabalhos de natureza prática, principalmente nos oriundos de pesquisa acadêmica: 21 publicações estão ligadas à academia, o que sugere disseminação do Bick na universidade, fundamentalmente a partir de 2001, novamente com predominância do eixo Sul-Sudeste (dois trabalhos do Nordeste, nenhum do Norte).

A Psicanálise foi o referencial mais utilizado, com predominância da Escola Inglesa (Klein, Bick, Bion, Winnicott), possivelmente devido aos aspectos históricos e epistemológicos que caracterizam o método e até hoje 
referenciam teoricamente grande parte das pesquisas com o Bick. No entanto, observou-se uso de referenciais teóricos alternativos, embora de modo discreto, na compreensão de fenômenos ligados à aplicação do Bick. Estima-se que a complexa e vasta experiência criada com o método pode ser aprofundada e discutida transdisciplinarmente por meio de conceitos e construtos advindos de paradigmas diversos.

Autores brasileiros vêm aplicando o Bick em contextos alternativos, explorando, ampliando e revitalizando sua aplicação preventiva, terapêutica e avaliativa, favorecendo a reflexão nas diferentes vertentes que o método oferece. A área de saúde figura fortemente nas publicações, enquanto a preocupação com aspectos sociais apareceu de modo discreto. Observações sobre variações culturais no desenvolvimento psíquico não encontraram representantes, nicho talvez inexplorado no Brasil.

No Bick aplicado em pesquisas acadêmicas, identificouse variedade de settings: modificações no local (apesar de a maioria remeter às residências das famílias), na quantidade, na frequência e na duração das observações, na supervisão (quando houve) e quanto aos participantes. Pesquisas com material secundário estiveram presentes, embora em menor quantidade. Quando o Bick foi utilizado junto com outra técnica ou instrumento, entrevistas e dados da história de vida foram os únicos. Algumas aproximaram o Bick dos métodos qualitativos, desenvolvendo combinações com técnicas de campo e análise dos resultados.

Alguns trabalhos fundamentam criativas e interessantes pesquisas com abordagens criadas a partir do Bick. Noutros, verificam-se lacunas quanto à especificidade na aplicação e/ou modificação no Bick, por exemplo, no que concerne ao número e frequência das observações, formato da supervisão, preparo do observador, análise desenvolvida. Foram retomados aspectos do debate sobre a pesquisa psicanalítica, reinterpretada na complexidade das implicações epistemológicas do pesquisar com Psicanálise no contexto universitário.

Embora adaptações, ampliações e combinações carreguem o salutar germe da criatividade, há que se refletir sobre as possíveis implicações, sob o risco de comprometer a essência da técnica, o próprio objeto de observação. Sem os três momentos do método, não há pesquisa possível com o Bick, o qual já não existe. O primeiro passo para o conhecimento produzido em bases férteis e confiáveis deve ser o entendimento das características epistemológicas, possibilidades aplicacionais, vantagens e limitações do método, para que seu potencial seja expandido adequadamente, minimizando o risco de diluir e perder a essência da Psicanálise, condição ao diálogo transdisciplinar.

\section{REFERÊNCIAS}

Amorim, M. L. G. (2004). A observação de bebês, segundo Esther Bick: Uma contribuição à formação e à clínica psicanalítica (Dissertação de mestrado). Universidade de São Marcos, São Paulo.

Appio, D., \& Matte, L. D. S. (1999). Método Esther Bick: Um caminho para a pesquisa qualitativa. Aletheia, 10, 51-58.

Araújo, C. A. S. (2004). A depressão pós-parto e sua interferência no desenvolvimento da função materna. Psicologia Revista, 13(2), 11-18.

Bick, E. (1964). Notes on infant observation in psychoanalytic training. International Journal of Psychoanalysis, 45, 558-666.

Bustamante, V., \& McCallum, C. (2014). Feeding practices, healthcare and kinship during the first year of life. Estudos de Psicologia, 31(3), 425-435.

Caron, N. A. (1995). Fundamentos teóricos para a aplicação do método de E. Bick. Revista Brasileira de. Psicanálise, 29(2), 283-292.

Caron, N. A. (Org.). (2000). A relação pais-bebê: Da observação à clínica. São Paulo: Casa do Psicólogo.

Caron, N., Lopes, R. C. S., Steibel, D., \& Donelli, T. S. (2012). Writing as a challenge in the observer's journey through the Bick method of infant observation. Infant Observation, 15(3), 221-230.

Caron, N. A., \& Lopes, R. C. S. (no prelo). Mapeamento dos grupos de observação de bebês segundo o método Bick no Brasil.

Casseb, A. R. (1993). Repensando a relação médico-paciente a luz do método observacional-compreensivo: Considerações balintianas sobre a prática médica em consultórios de médicos de família (Tese de doutorado). Universidade Estadual de Campinas, São Paulo, Brasil.

Corte, J. (2005). O método de observação da relação mãe-bebê, de Esther Bick, e a formação do psicoterapeuta (Dissertação de mestrado). Pontifícia Universidade Católica do Rio Grande do Sul, Porto Alegre, Rio Grande do Sul, Brasil.

Costa, M. V. S. (2000). O método de observação de bebês modelo Esther Bick. (Dissertação de mestrado). Instituto Fernandes Figueira, Rio de Janeiro, Rio de Janeiro, Brasil.

Demo, P. (2001). Sujeito e objeto. In Pesquisa e informação qualitativa: Aportes metodológicos (pp. 23-34). Campinas, SP: Papirus.

Donelli, T. M. S., \& Lopes, R. C. S. (2013). Descortinando a vivência emocional do parto através do Método Bick. PsicoUSF, 18(2), 289-298.

Escosteguy, N. (2012). Observação de bebês curricular no CEAPIA: Método Esther Bick modificado. Publicação CEAPIA, 21(21), 85-94.

Falcão, L. (1999). A “observação de bebês" e intervenções precoces: A prevenção através do pediatra. Publicação CEAPIA, 12(12), 134-143.

Farias, E. P., \& Tucherman, S. E. (1988). A observação da relação mãe-bebê e a formação analítica. Revista Brasileira de Psicanálise, 22, 595-609.

Freitas, C. H. B., \& Ângulo, M. (2006). Relação mãe-bebê logo após o parto e na amamentação: A identificação projetiva realista, pelos sentimentos e sensações do observador. Psicólogo Informação, 10(10), 83-101.

Freud, S. (1980). Dois verbetes de enciclopédia. In Além do principio de prazer, Psicologia de grupo e outros trabalhos (Vol. 18, J. Salomão, Trad, versão eletrônica da Edição standard brasileira das obras psicológicas completas de Sigmund Freud). Rio de Janeiro: Imago. (Original publicado em 1923)

Golin, G., Benetti, S. P. C., \& Donelli, T. M. S. (2011). Um estudo sobre o acolhimento precoce inspirado no método Bick. Psicologia em Estudo, 16(4), 561-569. 
Golin, G., \& Benetti, S. P. C. (2013). Acolhimento precoce e o vínculo na institucionalização. Psicologia: Teoria e Pesquisa, 29(3), 241-248.

Grillo, L. W. (2006). Quando é chegado o fim? Reflexões sobre a experiência de término de uma observação pais-bebê. Publicação CEAPIA, 15(15), 79-89.

Guimarães, M. L. Z. (1998). Observação da relação mãe-bebê. Alter, 17(1), 71-78.

Iribarry, I. N. (2003). O que é pesquisa psicanalítica? Ágora, 6(1), 115-138.

Laks, D., Filipouski, G., Germani, H., \& Valente, J. (2009). Colcha de retalhos: Uma breve reflexão sobre o tornar-se observador. Revista Brasileira de Psicoterapia, 11(3), 316-324.

Lisondo, A., Spessoto, L. B., \& Mattos, L. T. L. (2012). O método de observação de bebês de Esther Bick e seu potencial diagnóstico através da comparação de dois casos observados. Revista de Psicanálise SPPA, 19(3), 543-563.

Lisondo, A. B. D. (2007). O método de observação de bebês Esther Bick, a Psicanálise de crianças e adolescentes: Ateliê privilegiado para a Psicanálise contemporânea. Psicanálise, 9(12), 321-340.

Lopes, R. C. S., Caron, N. A., Steibel, D., \& Donelli, T. M. S. (2012). Desafios ao percurso do pesquisador psicanalítico: reflexões a partir da pesquisa com o método Bick de observação de bebês. In M. M. K. Macedo \& B. S. G. Werlang (Orgs.), Psicanálise e universidade: Potencialidades teóricas no cenário da pesquisa (pp. 212-229). Porto Alegre: EDIPUCRS.

Loureiro, I. (2002). Sobre algumas disposições metodológicas de inspiração freudiana. In E. F. Queiroz \& A. R. R. Silva (Orgs.), Pesquisa em psicopatologia fundamental (pp. 143-156). São Paulo: Escuta.

Lowenkron, T. S. (2004). O objeto da investigação psicanalítica. In F. Herrmann \& T. S. Lowenkron (Orgs.), Pesquisando com o método psicanalítico (pp. 21-31). São Paulo: Casa do Psicólogo.

Maltz, R. S. (2003). Observação de bebês - método Bick - uma vivência emocional significativa para a criatividade. Revista Brasileira de Psicanálise, 37(2/3), 631-646.

Mélega, M. P. (1997). Pesquisa da atividade simbólica com ênfase no estudo do brincar: método de observação mãe-bebê Esther Bick. Revista Brasileira de Psicanálise, 31(3), 745-760.

Mélega, M. P. (2001). A contribuição de Esther Bick à clínica psicanalítica. Psyche, 5(7), 69-83.

Mélega, M. P., \& Sonzongo, M. C. (Orgs.). (2008). O olhar e a escuta para compreender a primeira infância. São Paulo: Casa do Psicólogo.

Oliveira, N. R. (2011). Costurando rupturas: O trauma na clínica psicanalítica com uma criança (Dissertação de mestrado). Universidade de Brasília, Brasília, Distrito Federal, Brasil.

Oliveira-Menegotto, L. M., Menezes, C. C., Caron, N. A. C., \& Lopes, R. C. S. (2006). O método Bick de observação de bebês como método de pesquisa. Psicologia Clínica, 18(2), 77-96.

Oliveira-Menegotto, L. M., \& Lopes, R. C. S. (2009). Tornar-se Poliana: o desamparo materno diante de seu bebê com síndrome de Down. Psico, 40(4), 449-457.

Oliveira-Menegotto, L. M., Lopes, R. C. S., \& Caron, N. A. (2010). O método Bick de observação da relação mãe-bebê: aspectos clínicos. Psicologia Clínica, 22(1), 39-55.

Pergher, D. N. Q., \& Cardoso, C. L. (2008). A experiência do aprendizado na observação da relação mãe-bebê-família. Psyche, 12(23). Recuperado de http://pepsic.bvsalud.org/scielo. php? script $=$ sci arttext\&pid $=$ S1415-11382008000200004

Queiroz, E. F. (2002). O estatuto do caso clínico. Pulsional, 15(157), 33-40.

Queiroz, E. F. (2005). Inclinar-se para a escuta e inclinar-se para a escrita. Pulsional, 18(184), 60-64.
Reid, S. (1997). The development of autistic defenses in an infant: The use of a single case study for research. Infant Observation, 1(1), 51-110.

Rhode M. (2004). Infant observation as research: cross-disciplinary links. Journal of Social Work Practice, 18(3), 283-98.

Rustin, M. (2006). Infant observation research: What have we learned so far? Infant Observation, 9(1), 35-52.

Rustin, M. (2012). Infant observation as a method of research. In K. Urwin \& J. Sternberg (Orgs.), Infant observation and research (pp. 13-22). London: Routledge.

Rustin, M. E. (2009). Esther Bick's legacy of infant observation at the Tavistock - Some reflections 60 years on. Infant Observation, 12(1), 29-41.

Safra, G. (1993). O uso de material clínico na pesquisa psicanalítica. In M. E. L. Silva (Org.), Investigação e psicanálise (pp. 119132). Campinas: Papirus.

Sampaio, M. A., Falbo, A. R., Feliciano, K. V. O, Camarotti, M. C., Rustin, M., \& Miller, L. (2012). Anthropological and psychoanalytical observation: Theoretical and methodological dialogues in a doctorate programme in mother and child health. Revista Brasileira de Saúde Materno-Infantil, 12(1), 75-81.

Santos, M. E. E. A. (2012). Efeitos do luto materno na relação mãe-bebê (Dissertação de mestrado). Universidade de São Paulo, São Paulo, São Paulo, Brasil.

Santos, A. C. S. L., \& Pedroso, J. S. (2017). As adaptações no Brasil do método Bick de observação em pesquisas empíricas. Revista da SPAGESP, 18(1), 101-114.

Scorsolini-Comin, F., Nedel, A. Z., \& Santos, M. A. (2011). De perto, de longe, de fora e de dentro: a formação do observador a partir de uma experiência com o método Bick. Psicologia Clínica, 23(2), 151-170.

Siqueira, L. A., \& Andriatte, A.M. (2001). Um estudo observacional sobre o vínculo afetivo de bebês abrigados em instituições sociais. Boletim de Iniciação Científica em Psicologia, 2(1), $8-25$.

Souza, M. S. I. (2008). Intervenções terapêuticas conjuntas na unidade de terapia intensiva neonatal e pediátrica (Dissertação de mestrado). Pontifícia Universidade Católica de São Paulo, São Paulo, Brasil.

Stake, R.E. (1994). Case Studies. In N.K. Dezin \& Y.S. Lincoln (Eds), Handbook of qualitative research (pp. 236-247). Bevery Hills, CA: Sage Publications.

Steibel, D. (2011). Considerações sobre experiências precoces e a construção do self. Psicoterapia Psicanalítica, 13, 165-174.

Stocche, T. M. (2003). Observação da relação mãe-bebê: Método Esther Bick. Revista Brasileira de Psicanálise, 37(2/3), 647654.

Stoiani, L. P. (2007). As interações corporais entre a mãe e o bebê nos primórdios da constituição psíquica: Um estudo a partir da experiência de observação na técnica Esther Bick (Dissertação de mestrado). Universidade de São Paulo, São Paulo, Brasil.

Tavares, M. E. B. P. (2007). Situações triangulares em gêmeos durante o primeiro ano de vida: Conjecturas sobre o complexo de Édipo (Tese de doutorado). Universidade de São Paulo, São Paulo, Brasil.

Urwin, C., \& Sternberg, J. (Orgs.). (2012). Infant observation and research. London: Routledge.

Vivian, A. G. (2006). O desenvolvimento emocional de um bebê em uma família numerosa: Uma aplicação do método Bick (Dissertação de mestrado). Porto Alegre: Universidade Federal do Rio Grande do Sul.

Yin, R. K. (2005). Estudo de caso: Planejamento e métodos $\left(3^{\mathrm{a}}\right.$ edição). Porto Alegre: Bookman. 